\title{
The association between dietary macronutrient intake and the prevalence of the metabolic syndrome
}

\author{
Michael R. Skilton ${ }^{1,2 *}$, Martine Laville ${ }^{1,3}$, Anne E. Cust ${ }^{1,4}$, Philippe Moulin ${ }^{3,5}$ and Fabrice Bonnet ${ }^{1,3}$ \\ ${ }^{1}$ Human Nutrition Research Centre (CRNH), Université Claude Bernard Lyon 1, Lyon, France \\ ${ }^{2}$ Baker Heart Research Institute, PO Box 6492, St Kilda Road Central, Melbourne, Vic 8008, Australia \\ ${ }^{3}$ INSERM U449-INRA 1235, Lyon, France \\ ${ }^{4}$ School of Public Health, University of Sydney, Sydney, Australia \\ ${ }^{5}$ Department of Medicine, Diabetology-Endocrinology Cardiovascular Hospital Louis Pradel, Lyon, France \\ (Received 16 August 2007 - Revised 14 November 2007 - Accepted 19 November 2007 - First published online 15 January 2008)
}

\begin{abstract}
We examined the association of dietary carbohydrates, protein, fat (including fatty acid subtypes) and alcohol with the metabolic syndrome and its components, in a cross-sectional study of 1626 patients with at least one cardiovascular risk factor. Multivariate nutrient density substitution models were used to examine the associations between macronutrients (assessed by $24 \mathrm{~h}$ dietary recall) and the metabolic syndrome. These models express the effects of 'substituting' one macronutrient for another without altering total energy intake. Increases in carbohydrates offset by isoenergetic decreases in either fat or protein were associated with a decrease in the prevalence of the metabolic syndrome (OR 0.87 (95\% CI 0.81, 0.93), $P<0.0001$; OR 0.70 (95\% CI 0.61, 0.79), $P<0.0001$, per $5 \%$ energy intake respectively). Increased intake of dietary fat at the expense of dietary protein was also associated with a decreased prevalence of the metabolic syndrome (OR 0.80 (95\% CI $0.70,0.92)$, $P=0.002$ per $5 \%$ energy intake). There were no statistically significant differences between fatty acid subtypes $(P>0 \cdot 10)$. Consumption of up to one standard alcoholic drink per $d$ was associated with a lower prevalence of the metabolic syndrome when compared with non-drinkers (OR 0.67 (95\% CI 0.50, 0.89), $P=0.006$ ); however, these benefits were weakened with higher levels of alcohol intake $(P=0.10$ for one to three drinks and $P=0.29$ for $>$ three drinks). Thus, a diet high in carbohydrates, low in fat and protein, with low-to-moderate alcohol intake, is associated with a reduced prevalence of the metabolic syndrome.
\end{abstract}

Metabolic syndrome: Macronutrient intake: Diet

The metabolic syndrome (MetS) is a clustering of risk factors that augment the risk of CVD and type 2 diabetes ${ }^{(1,2)}$. Dietary factors can influence all five of the MetS components - abdominal obesity, raised serum TAG, low HDL-cholesterol, raised fasting blood glucose and raised blood pressure. Thus dietary modification presents a powerful means by which to both prevent and treat the MetS. There is a growing body of literature describing the association between macronutrient intake and the prevalence of the MetS ${ }^{(3-9)}$. However, only a couple of these studies have investigated the role of dietary composition after adjusting for total dietary energy intake ${ }^{(3,8)}$. This is the equivalent of using 'isoenergetic' conditions in intervention trials, and presents results that are more readily applicable than those from non-energy adjusted analyses ${ }^{(10)}$. Furthermore, many of the studies examining this association have adjusted their statistical models for $\mathrm{BMI}^{(4-7)}$, despite abdominal obesity being a component of the MetS. These adjustments may markedly alter the results of regression models. For example, regarding the association between carbohydrate consumption and the prevalence of the MetS, studies that adjust for BMI have shown a positive association ${ }^{(4-6)}$, whereas no such association was found in the only study that we identified that did not adjust for BMI but did adjust for total energy intake ${ }^{(3)}$.

Statistical methods exist that allow for the theoretical substitution of one macronutrient for another within an isoenergetic environment. For example, these techniques allow us to study whether increasing carbohydrate, while simultaneously decreasing protein, influences the estimated probability of having the MetS. This information may provide more pertinent and readily applicable information than is currently available.

Thus we sought to examine the association of the dietary proportion of carbohydrates, protein, fat (including fatty acid subtypes) and alcohol, with the MetS and its individual components in a cohort of subjects at an increased risk of cardiovascular events.

Abbreviations: IDF, International Diabetes Federation; MetS, metabolic syndrome; NCEP-ATPIII, National Cholesterol Education Program - Adult Treatment Panel III.

* Corresponding author: Dr Michael Skilton, fax +61 385321100 , email michael.skilton@baker.edu.au 


\section{Experimental methods}

\section{Population}

We studied 1626 patients aged $30-80$ years, referred by a primary care physician to our out-patient Centre for Prevention and Detection of Atherosclerosis (Lyon, France), between 1995 and 2000. All patents were referred on the basis of having at least one traditional cardiovascular risk factor (hypercholesterolaemia, hypertension, diabetes, obesity, tobacco smoking or a family history of CVD). We certify that all applicable institutional and governmental regulations concerning the ethical use of human volunteers were followed during this research. All patients provided written informed consent.

\section{Dietary assessment}

Dietary intake was assessed via a $24 \mathrm{~h}$ dietary recall, assisted by a registered dietitian. Dietary composition was analysed using the GENI software package (version 2; Micro 6, Nancy, France). Measured dietary components included protein, fat (including SFA, MUFA and PUFA), carbohydrates and alcohol intake, in addition to dietary cholesterol. Alcohol consumption was classified as 'non-drinkers' $(0 \mathrm{~g} / \mathrm{d})$, up to one standard drink per d (' $\leq$ one drink'; $1-14 \mathrm{~g} / \mathrm{d}$ ), between one and three standard drinks per d ('one to three drinks'; $15-42 \mathrm{~g} / \mathrm{d}$ ), and greater than three standard drinks per $\mathrm{d}$ (' $>$ three drinks'; more than $42 \mathrm{~g} / \mathrm{d}$ ). Trans fatty acids were estimated as the difference between total fat and the combined quantity of SFA, MUFA and PUFA. As such, trans fatty acids were used only as an adjustment variable, and not as a dietary component of interest. Energy was calculated using the Atwater factors of $16.74 \mathrm{~kJ} / \mathrm{g}(4.0 \mathrm{kcal} / \mathrm{g})$ for protein, $37.24 \mathrm{~kJ} / \mathrm{g}(8.9 \mathrm{kcal} / \mathrm{g})$ for fat, $16.74 \mathrm{~kJ} / \mathrm{g}(4.0 \mathrm{kcal} / \mathrm{g})$ for carbohydrate and $29.29 \mathrm{~kJ} / \mathrm{g}(7 \mathrm{kcal} / \mathrm{g})$ for alcohol.

\section{Assessment of metabolic factors}

Blood pressure was measured at rest using an automatic sphygmomanometer. The average of three readings was used in these analyses. Waist circumference was measured at the level of the iliac crest. Venous blood was sampled using standard venepuncture techniques, after the patient had fasted overnight. Measurement of HDL-cholesterol, TAG and glucose were undertaken using standard laboratory techniques.

\section{Metabolic syndrome}

The MetS was diagnosed using the International Diabetes Federation (IDF) definition ${ }^{(11)}$. For a diagnosis of the MetS using the IDF definition, abdominal obesity must be present, in addition to two or more of the other four factors. The cut-points for the five factors are: waist circumference $\geq 94 \mathrm{~cm}$ for men and $\geq 80 \mathrm{~cm}$ for women; $T A G \geq 1.7 \mathrm{mmol} / 1$; systolic $\mathrm{BP} \geq 130 \mathrm{mmHg}$ or diastolic $\mathrm{BP} \geq 85 \mathrm{mmHg}$; fasting glucose $\geq 5.6 \mathrm{mmol} / \mathrm{l} ; \mathrm{HDL}<1.03 \mathrm{mmol} / \mathrm{l}$ in men and $<1.30 \mathrm{mmol} / 1$ in women ${ }^{(11)}$. Furthermore, all individuals receiving pharmacological treatment for hypertension, hypertriacylglycerolaemia or low HDL-cholesterol, and all individuals previously diagnosed with type 2 diabetes, are considered as positive for those respective components. In France, fibrates are principally prescribed to treat hypertriacylglycerolaemia, and thus fibrate use was considered evidence of hypertriacylglycerolaemia only.

\section{Assessment of socio-economic and lifestyle factors}

A structured questionnaire administered by a study physician was used to determine employment, marital and smoking status, physical activity and medical history including prior CVD. Employment status was categorised as unemployed, blue-collar employees, white-collar professionals, and retired. Marital status was categorised as single/never married, married/de facto, widowed, and separated. Smoking status was categorised as subjects who never smoked, current smokers, exsmokers who quit within the previous 2 years, ex-smokers who quit between 2 and 5 years prior, and ex-smokers who quit more than 5 years prior. The level of physical activity was categorised into three groups according to the number of $20 \mathrm{~min}$ sessions of moderate or intense activity per week: (1) high level of physical activity - three or more sessions; (2) moderate level of physical activity - one or two sessions; (3) sedentary - less than one session.

\section{Statistical analyses}

Statistical significance was inferred at two-tailed $P<0.05$. Student's $t$ tests for continuous variables and $\chi^{2}$ analyses for dichotomous variables were used to compare subject characteristics between subjects with and without the MetS.

To examine the associations between macronutrients and the MetS, multivariate nutrient density models and multivariate nutrient density substitution models were created as described in detail elsewhere ${ }^{(12)}$. Briefly, logistic regression models were constructed, with the presence of the MetS as the dependent variable. These models were adjusted for total energy intake to allow for the study of the effects of dietary composition. One macronutrient is included as the independent variable of interest. Another macronutrient is excluded from the model. The model is adjusted for the other macronutrients. Thus by controlling for total energy intake and the other macronutrients, the OR for the independent variable of interest represents the OR for an increase in the macronutrient of interest whilst simultaneously reducing an isoenergetic amount of the macronutrient excluded from the model. For example, to examine the substitution of carbohydrates for protein, carbohydrates are included as the independent variable of interest, protein is excluded from the model, and the model is adjusted for dietary fat intake, alcohol intake and total energy intake. The OR for carbohydrates represents substituting carbohydrates for an isoenergetic quantity of dietary protein. Macronutrients were entered into these models as a percentage of total dietary energy intake, except in the models examining the influence of alcohol, in which alcohol intake has been grouped according to US standard drink units (14 $\mathrm{g}$ alcohol), both to enhance the understanding and application of these findings, and also because alcohol is frequently associated with disease in a non-linear fashion. All models were further adjusted for physical activity, to adjust for other aspects of energy balance ${ }^{(13)}$, in addition to age, sex, socio-economic factors and smoking status. Adjusting these models for dietary cholesterol intake did not modify these results (data not shown). Models examining 
the non-abdominal obesity components of the MetS were further adjusted for BMI.

The potential influence of sex, physical activity (sedentary compared with high level), age (above compared with below the median) and alcohol intake (up to one drink per d compared with non-drinkers) on the associations between dietary factors and the MetS was examined using a test of interaction as described elsewhere ${ }^{(14)}$. All other statistical analyses were undertaken using StatView for Windows (version 5.0; SAS Institute Inc., Cary, NC, USA).

\section{Results}

General subject characteristics are displayed in Table 1. Of the 1626 subjects, $983(60 \%)$ were diagnosed with the MetS.

We used a series of multivariate nutrient density models to examine the associations between dietary macronutrient content and the MetS. The percentage of energy derived from carbohydrate intake was inversely associated, and that of both protein and fat positively associated, with the prevalence of the IDF MetS in adjusted models (Table 2). We then studied the association of the relative proportions of dietary carbohydrate, fat and protein with the prevalence of the MetS and its components in energy-controlled substitution models (Table 3 and Fig. 1). These models indicate that increased carbohydrate intake offset by an isoenergetic decrease in either fat or protein is associated with a decreased prevalence of the IDF MetS (both $P<0 \cdot 0001$ ), and that increased dietary fat at the expense of dietary protein intake also decreased the probability of the IDF MetS $(P=0.002)$. We found that there was significant heterogeneity in some of these associations between diabetic and non-diabetic subjects, especially with regards to protein intake (substitution of carbohydrates for protein, non-diabetic: OR for MetS $=0.68(95 \%$ CI 0.58, 0.80), diabetic: OR 0.98 (95\% CI 0.75, 1.27); $P_{\text {heterogeneity }}=0.02$; substitution of fat for protein, non-diabetic: OR for MetS $=0.74(0.62,0.88)$, diabetic: OR 1.16 $\left.(0.87,1.54) ; P_{\text {heterogeneity }}=0.009\right)$, but not for the substitution of carbohydrate for fat, $P_{\text {heterogeneity }}=0 \cdot 31$.

We then examined the association between the IDF MetS and dietary fatty acids. We created a substitution model including MUFA, PUFA and SFA, in addition to total energy intake, trans fatty acids, and alcohol intake, and further adjusted for physical activity, age, sex, socio-economic factors and smoking status. The OR for MUFA, PUFA and SFA in this model can be interpreted as being substituted for non-specified carbohydrates and protein. PUFA and SFA were both positively associated with the prevalence of the MetS (MUFA (5\% energy intake): OR 1.06 (95\% CI 0.91, 1.23 ), $P=0.46$; SFA (5\% energy intake): OR 1.19 (95\% CI $1.03,1.36), P=0.016$; PUFA (5\% energy intake): OR 1.23 (95\% CI 1.03, 1.47), $P=0.021$ ). The association of SFA with the MetS was weakened when the National Cholesterol Education Program - Adult Treatment Panel III (NCEPATPIII) definition was used (MUFA (5\% energy intake): OR 1.03 (95\% CI $0.89,1.20), P=0.68$; SFA (5\% energy intake): OR 1.08 (95\% CI $0.94,1.24), P=0.29$; PUFA (5\% energy intake): OR 1.23 (95\% CI 1.03, 1.47), $P=0.024)$.

Table 1. Subject characteristics, grouped by presence or absence of the metabolic syndrome (International Diabetes Federation (IDF) definition)

(Mean values and standard deviations)

\begin{tabular}{|c|c|c|c|c|c|c|c|}
\hline & & & \multicolumn{4}{|c|}{ IDF metabolic syndrome } & \multirow[b]{3}{*}{$P^{*}$} \\
\hline & \multicolumn{2}{|c|}{ Entire cohort } & \multicolumn{2}{|c|}{ No } & \multicolumn{2}{|c|}{ Yes } & \\
\hline & Mean & SD & Mean & SD & Mean & SD & \\
\hline \multicolumn{8}{|l|}{ Subjects } \\
\hline$n$ & \multirow{2}{*}{\multicolumn{2}{|c|}{1626}} & \multicolumn{2}{|c|}{643} & \multicolumn{2}{|c|}{983} & - \\
\hline$\%$ & & & \multicolumn{2}{|c|}{40} & \multicolumn{2}{|c|}{60} & \\
\hline Age (years) & $52 \cdot 1$ & $9 \cdot 8$ & $50 \cdot 2$ & $9 \cdot 8$ & $53 \cdot 4$ & $9 \cdot 6$ & $<0.0001$ \\
\hline \multicolumn{8}{|l|}{ Sex male } \\
\hline$n$ & \multicolumn{2}{|c|}{987} & \multicolumn{2}{|c|}{386} & \multicolumn{2}{|c|}{601} & 0.65 \\
\hline$\%$ & \multicolumn{2}{|c|}{61} & \multicolumn{2}{|c|}{60} & \multicolumn{2}{|c|}{61} & - \\
\hline Waist circumference $(\mathrm{cm})$ & $98 \cdot 6$ & 14.5 & 87.9 & $11 \cdot 6$ & $105 \cdot 5$ & $11 \cdot 7$ & $<0.0001$ \\
\hline $\mathrm{TAG}(\mathrm{mmol} / \mathrm{l})$ & 2.08 & $1 \cdot 61$ & 1.59 & $1 \cdot 12$ & $2 \cdot 40$ & $1 \cdot 79$ & $<0.0001$ \\
\hline HDL-cholesterol (mmol/l) & $1 \cdot 28$ & 0.41 & 1.45 & 0.45 & $1 \cdot 17$ & 0.34 & $<0.0001$ \\
\hline Systolic BP (mmHg) & $138 \cdot 4$ & $18 \cdot 5$ & $130 \cdot 3$ & $17 \cdot 7$ & $143 \cdot 7$ & $17 \cdot 0$ & $<0.0001$ \\
\hline Diastolic BP (mmHg) & $85 \cdot 0$ & $11 \cdot 1$ & $80 \cdot 6$ & $10 \cdot 4$ & $87 \cdot 9$ & $10 \cdot 6$ & $<0.0001$ \\
\hline Fasting glucose $(\mathrm{mmol} / \mathrm{l})$ & $6 \cdot 12$ & 2.59 & $5 \cdot 25$ & $2 \cdot 07$ & $6 \cdot 69$ & 2.74 & $<0.0001$ \\
\hline \multicolumn{8}{|l|}{ Diabetes } \\
\hline$n$ & \multicolumn{2}{|c|}{537} & \multicolumn{2}{|c|}{92} & \multicolumn{2}{|c|}{445} & $<0.0001$ \\
\hline$\%$ & \multicolumn{2}{|c|}{33} & \multicolumn{2}{|c|}{14} & \multicolumn{2}{|c|}{45} & \\
\hline Energy intake (kJ/d) & 8095 & 2725 & 7977 & 2468 & 8172 & 2880 & $0 \cdot 16$ \\
\hline Carbohydrate (\% energy) & $42 \cdot 0$ & $10 \cdot 0$ & $43 \cdot 6$ & $10 \cdot 2$ & $41 \cdot 1$ & $9 \cdot 8$ & $<0.0001$ \\
\hline Protein (\% energy) & $18 \cdot 1$ & $4 \cdot 8$ & $17 \cdot 5$ & $4 \cdot 6$ & $18 \cdot 5$ & 4.9 & 0.0001 \\
\hline Fat (\% energy) & 33.9 & $8 \cdot 3$ & 33.0 & $8 \cdot 3$ & $34 \cdot 6$ & $8 \cdot 3$ & 0.0001 \\
\hline SFA (\% energy) & $13 \cdot 3$ & $4 \cdot 6$ & $12 \cdot 9$ & $4 \cdot 6$ & $13 \cdot 6$ & 4.5 & 0.001 \\
\hline MUFA (\% energy) & $12 \cdot 4$ & $4 \cdot 0$ & $12 \cdot 1$ & $4 \cdot 2$ & $12 \cdot 6$ & $3 \cdot 9$ & 0.014 \\
\hline PUFA (\% energy) & $5 \cdot 3$ & $3 \cdot 1$ & $5 \cdot 1$ & $2 \cdot 8$ & $5 \cdot 4$ & $3 \cdot 2$ & 0.037 \\
\hline Alcohol (\% energy) & $5 \cdot 9$ & $10 \cdot 1$ & $6 \cdot 0$ & $9 \cdot 9$ & 5.9 & $10 \cdot 1$ & 0.90 \\
\hline
\end{tabular}

BP, blood pressure.

${ }^{*} P$ values from Student's $t$ test for continuous variables and $\chi^{2}$ test for sex and diabetes. 
Table 2. The association of dietary carbohydrate, protein and fat with the metabolic syndrome and metabolic syndrome components*

(Odds ratios and $95 \%$ confidence intervals)

\begin{tabular}{|c|c|c|c|c|c|c|c|c|c|c|c|c|c|c|c|c|c|c|}
\hline & \multicolumn{3}{|c|}{ Metabolic syndrome } & \multicolumn{3}{|c|}{ Abdominal obesity } & \multicolumn{3}{|c|}{ Raised TAG† } & \multicolumn{3}{|c|}{ Low HDL† } & \multicolumn{3}{|c|}{ Raised blood pressure $†$} & \multicolumn{3}{|c|}{ Impaired fasting glucose $†$} \\
\hline & OR & $95 \% \mathrm{Cl}$ & $P$ & OR & $95 \% \mathrm{Cl}$ & $P$ & OR & $95 \% \mathrm{Cl}$ & $P$ & OR & $95 \% \mathrm{Cl}$ & $P$ & OR & $95 \% \mathrm{Cl}$ & $P$ & OR & $95 \% \mathrm{Cl}$ & $P$ \\
\hline Carbohydrate & 0.83 & $0.78,0.88$ & $<0.0001$ & 0.78 & $0.73,0.84$ & $<0.0001$ & 1.07 & $1 \cdot 00,1 \cdot 14$ & 0.034 & 1.07 & $1 \cdot 01,1 \cdot 15$ & 0.027 & 1.02 & $0.94,1 \cdot 10$ & 0.69 & 0.83 & $0.78,0.89$ & $<0.0001$ \\
\hline Protein & 1.41 & $1 \cdot 24,1 \cdot 60$ & $<0.0001$ & 1.48 & $1 \cdot 27,1 \cdot 71$ & $<0.0001$ & 0.97 & $0.86,1 \cdot 10$ & 0.66 & 1.01 & $0.90,1.15$ & 0.82 & 0.98 & $0.84,1 \cdot 14$ & 0.75 & 1.18 & $1.04,1.35$ & 0.012 \\
\hline Fat & 1.13 & $1.06,1.21$ & 0.004 & 1.20 & $1.11,1.30$ & $<0.0001$ & 0.93 & $0.87,1.00$ & 0.038 & 0.91 & $0.85,0.98$ & 0.010 & 0.99 & $0.91,1.08$ & 0.80 & 1.18 & $1 \cdot 10,1 \cdot 27$ & $<0.0001$ \\
\hline
\end{tabular}

${ }^{*}$ Carbohydrate, protein or fat is included as the independent variable of interest. The metabolic syndrome was defined using the International Diabetes Federation definition. Macronutrients were entered as percentage of total energy intake. The results are presented as OR for presence of the metabolic syndrome per $5 \%$ change in proportion of dietary energy. All models were adjusted for age, sex, physical activity, marital status, employment status, smoking

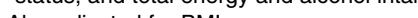

Table 3. The association of dietary carbohydrate, protein and fat with the metabolic syndrome and metabolic syndrome components*

(Odds ratios and $95 \%$ confidence intervals)

\begin{tabular}{|c|c|c|c|c|c|c|c|c|c|c|c|c|c|c|c|c|c|c|}
\hline & \multicolumn{3}{|c|}{ Metabolic syndrome } & \multicolumn{3}{|c|}{ Abdominal obesity } & \multicolumn{3}{|c|}{ Raised TAG† } & \multicolumn{3}{|c|}{ Low HDL† } & \multicolumn{3}{|c|}{ Raised blood pressure† } & \multicolumn{3}{|c|}{ Impaired fasting glucose $†$} \\
\hline & OR & $95 \% \mathrm{Cl}$ & $P$ & OR & $95 \% \mathrm{Cl}$ & $P$ & OR & $95 \% \mathrm{Cl}$ & $P$ & OR & $95 \% \mathrm{Cl}$ & $P$ & OR & $95 \% \mathrm{Cl}$ & $P$ & OR & $95 \% \mathrm{Cl}$ & $P$ \\
\hline $\begin{array}{l}\text { †Carbohydrate } \\
\downarrow \text { Protein }\end{array}$ & 0.70 & $0.61,0.79$ & $<0.0001$ & 0.66 & $0.57,0.77$ & $<0.0001$ & 1.04 & $0.92,1.18$ & 0.51 & 1.00 & $0 \cdot 88,1 \cdot 13$ & 0.99 & 1.03 & $0.88,1 \cdot 20$ & 0.73 & 0.81 & $0.71,0.93$ & 0.002 \\
\hline $\begin{array}{l}\uparrow \text { Carbohydrate } \\
\downarrow \text { Fat }\end{array}$ & 0.87 & $0.81,0.93$ & $<0.0001$ & 0.82 & $0.76,0.89$ & $<0.0001$ & 1.08 & $1.01,1.15$ & 0.033 & $1 \cdot 10$ & $1 \cdot 02,1 \cdot 18$ & 0.011 & 1.01 & $0.93,1.10$ & 0.77 & 0.83 & $0.78,0.90$ & $<0.0001$ \\
\hline $\begin{array}{l}\uparrow \text { Fat } \\
\downarrow \text { Protein }\end{array}$ & 0.80 & $0.70,0.92$ & 0.002 & 0.81 & $0.69,0.95$ & 0.009 & 0.97 & $0.85,1 \cdot 11$ & 0.62 & 0.91 & $0.80,1.05$ & 0.20 & 1.02 & $0.86,1 \cdot 20$ & 0.86 & 0.98 & $0.85,1 \cdot 13$ & 0.74 \\
\hline
\end{tabular}

Substitution model where carbohydrate, protein and fat are included as either: the variable of interest $(\uparrow)$; are excluded from the model, thus being the macronutrient substituted for $(\downarrow)$; or are adjusted for as a covariate. The metabolic syndrome was defined using the International Diabetes Federation definition. Macronutrients were entered as percentage of total energy intake. The results are presented as OR for presence of the metabolic syndrome per $5 \%$ change in proportion of dielary energy. The OR for the 'opposite' substitution is the inverse of that presented, and the $P$ value is the same. For example, the OR for the metabolic syndrome when substituting fat for carbohydrates $=1.15(95 \% \mathrm{Cl} 1.07,1.23)(P<0.0001)$. All models were adjusted for age, sex, physical activity, marital status, employment status, smoking status, and total energy and alcohol intake.

†Also adjusted for BMI. 


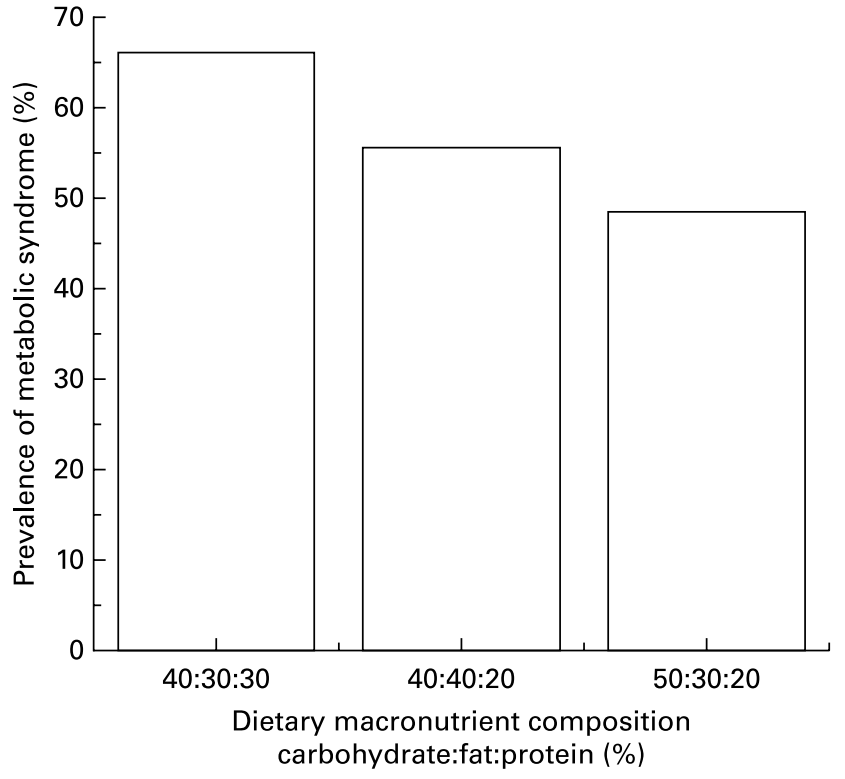

Fig. 1. Dietary macronutrient composition and prevalence of the metabolic syndrome (International Diabetes Federation definition). Results were derived from the substitution models in Table 3, and are indicative of a 50-year-old male at high-risk of CVD consuming $8368 \mathrm{~kJ}(2000 \mathrm{kcal})$ per $\mathrm{d}$.

To directly compare these dietary fatty acids, substitution models were created that adjusted for total energy, carbohydrate intake, protein intake, trans fatty acids and alcohol intake, while sequentially excluding one of the dietary fatty acid classes, thus substituting these dietary fatty acids for one another. Using these models, we found no statistically significant differences between SFA, MUFA and PUFA (Table 4).

Finally, we examined the association of alcohol intake with the prevalence of the MetS. To provide readily interpretable results, we separated alcohol intake into categories based on standard drinks. We created a model substituting energy from alcohol for that from non-specified macronutrients by adjusting for total energy intake and physical activity, in addition to age, sex, marital status, employment status and smoking status. This model indicated that consumption of up to one standard drink per $\mathrm{d}$ was associated with a marked lower prevalence of the IDF MetS when compared with nondrinkers (OR 0.67 (95\% CI 0.50, 0.89); $P=0.006$ ). This returned somewhat towards the levels of non-drinkers with higher alcohol intake (one to three drinks per d: OR 0.79 (95\% CI $0.59,1.05), P=0.10 ;>$ three drinks per d: OR 0.83 (95\% CI $0.58,1.17) ; P=0.29$ ), although this was not the case when the MetS was diagnosed using the NCEP-ATPIII criteria ( $\leq$ one drink per d: OR 0.65 (95\% CI $0.48,0.86$ ), $P=0.003$; one to three drinks per d: OR 0.73 (95\% CI 0.55 , $0.98), P=0.034$; $>$ three drinks per d: OR 0.68 (95\% CI $0.48,0.96), P=0.030$; as compared with non-drinkers). We then created a model adjusted for fat, carbohydrate and protein intake (as crude kJ), age, sex, socio-economic factors and smoking status, but neither total energy intake nor physical activity, thus examining the influences of alcohol under nonisoenergetic and non-energy-balanced conditions. Despite the potential for increased energy intake with higher alcohol consumption, the results from this model were similar to the previous energy-controlled model (IDF definition $-\leq$ one drink

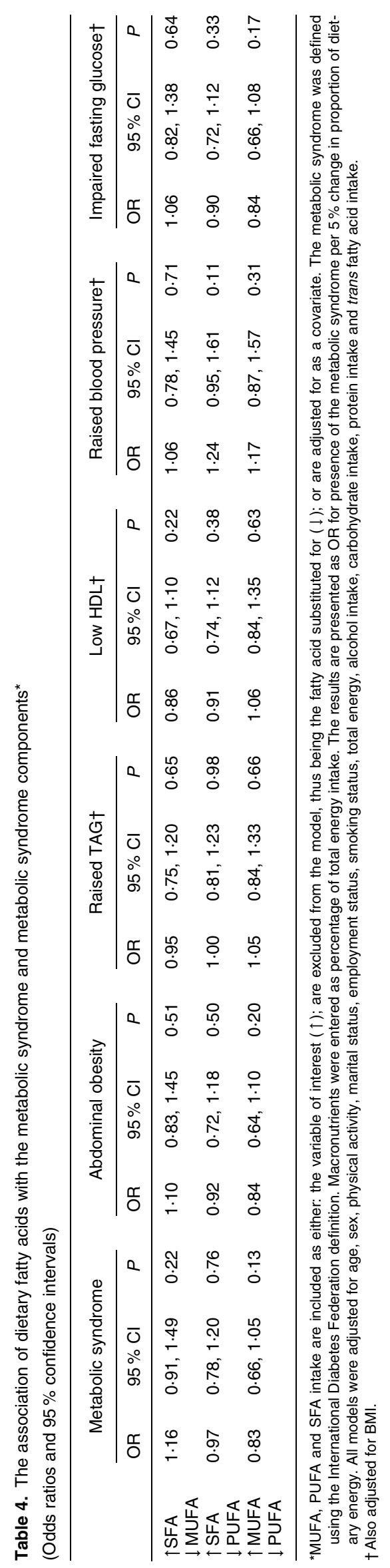


per d: OR $0.66(95 \%$ CI $0.50,0.89), P=0.006$; one to three drinks per d: OR 0.79 (95\% CI 0.59, 1.05), $P=0.11$; $>$ three drinks per d: OR 0.83 (95\% CI 0.58, 1.19), $P=0.32$; as compared with non-drinkers). Finally, we examined the influence of substituting alcohol intake for individual macronutrients (Table 5). Substitution of up to one standard drink per d for carbohydrate intake was associated with a markedly reduced prevalence of the IDF MetS; however, these reductions were cancelled as alcohol consumption increased further. In contrast, when substituted for either fat or protein, all quantities of alcohol intake were associated with reduced rates of IDF MetS. We also examined individual MetS components (data not in tables). Increasing alcohol intake accompanied by decreases in any of the other macronutrients was associated with a decreased prevalence of low HDLcholesterol. Increasing alcohol intake when accompanied by a decrease in carbohydrate intake was associated with an increased prevalence of abdominal obesity and impaired fasting glucose. Conversely, increasing alcohol intake, when accompanied by a decrease in either fat or protein was associated with a decreased prevalence of abdominal obesity. There were no significant associations with either raised TAG or blood pressure.

Table 5. The association of dietary alcohol intake with the metabolic syndrome in an isoenergetic diet ${ }^{*}$

(Odds ratios and $95 \%$ confidence intervals)

\begin{tabular}{|c|c|c|c|}
\hline & \multicolumn{3}{|c|}{ Metabolic syndrome } \\
\hline & OR & $95 \% \mathrm{Cl}$ & $P$ \\
\hline $\begin{array}{l}\text { Non-drinker } \\
\text { \Carbohydrate }\end{array}$ & 1.00 & Referent & - \\
\hline $\begin{array}{l}\leq \text { One drink } \\
\downarrow \text { Carbohydrate }\end{array}$ & 0.70 & $0.52,0.94$ & 0.016 \\
\hline $\begin{array}{l}\text { One to three drinks } \\
\downarrow \text { Carbohydrate }\end{array}$ & 0.95 & $0 \cdot 71,1 \cdot 28$ & 0.74 \\
\hline $\begin{array}{l}>\text { Three drinks } \\
\downarrow \text { Carbohydrate }\end{array}$ & 1.30 & $0.89,1.90$ & 0.18 \\
\hline $\begin{array}{l}\text { Non-drinker } \\
\downarrow \text { Fat }\end{array}$ & 1.00 & Referent & - \\
\hline $\begin{array}{l}\leq \text { One drink } \\
\downarrow \text { Fat }\end{array}$ & 0.63 & $0.47,0.84$ & 0.002 \\
\hline $\begin{array}{l}\text { One to three drinks } \\
\downarrow \text { Fat }\end{array}$ & 0.70 & $0.51,0.96$ & 0.027 \\
\hline $\begin{array}{l}>\text { Three drinks } \\
\downarrow \text { Fat }\end{array}$ & 0.62 & $0.40,0.96$ & 0.032 \\
\hline $\begin{array}{l}\text { Non-drinker } \\
\downarrow \text { Protein }\end{array}$ & 1.00 & Referent & - \\
\hline $\begin{array}{l}\leq \text { One drink } \\
\downarrow \text { Protein }\end{array}$ & 0.57 & $0.43,0.77$ & 0.0002 \\
\hline $\begin{array}{l}\text { One to three drinks } \\
\downarrow \text { Protein }\end{array}$ & 0.55 & $0.39,0.76$ & 0.0003 \\
\hline $\begin{array}{l}>\text { Three drinks } \\
\downarrow \text { Protein }\end{array}$ & 0.35 & $0.21,0.60$ & 0.0001 \\
\hline
\end{tabular}

*Alcohol intake is expressed in standard drinks per $\mathrm{d}(14 \mathrm{~g}$ alcohol) and grouped as 'non-drinkers' ( $0 \mathrm{~g} / \mathrm{d})$, 'up to one standard drink per d' ( $\leq$ one drink; $1-14 \mathrm{~g} / \mathrm{d}$ ), between one and three standard drinks per d ('one to three drinks'; 15-42 g/d) and greater than three standard drinks per $d$ (' $>$ three drinks'; more than $42 \mathrm{~g} / \mathrm{d}$ ). Alcohol is the independent variable of interest in all models. Dietary carbohydrate, protein and fat intake are either excluded from the model, thus being the macronutrient substituted for $(\downarrow)$, or are adjusted for as a covariate. The metabolic syndrome was defined using the International Diabetes Federation definition. Results are presented as OR for presence of the metabolic syndrome. All models were adjusted for age, sex, physical activity, marital status, employment status, smoking status and total energy intake.
We found no evidence that the associations of individual macronutrients (carbohydrates, protein, fat, alcohol) with the IDF MetS were modified by sex, level of physical activity, age or alcohol intake $\left(P_{\text {heterogeneity }}>0.05\right.$ for all).

\section{Discussion}

The present study indicates that the proportion of dietary energy derived from carbohydrates is inversely associated with the prevalence of the MetS. Furthermore, in the present study the consumption of up to one standard alcoholic drink per d was associated with a lower prevalence of the MetS when compared with non-drinkers.

In contrast to the majority of previous studies examining the association between macronutrients and the $\operatorname{MetS}^{(4-7,9)}$, we have adjusted our statistical models for total dietary energy intake but not BMI. By adjusting for total energy intake, the present results can be interpreted as being representative of an isoenergetic diet, and thus indicate the role of dietary macronutrient proportion independent of the effects of energy intake. Regarding adjustment for BMI, abdominal obesity is considered by many as the cornerstone and major element driving the incidence of the MetS ${ }^{(15)}$. Adjusting for BMI, which is strongly correlated with waist circumference (correlation coefficient of 0.87 in our cohort), would largely remove the influence of abdominal obesity from the MetS, thus providing results that are primarily dependent on the association between macronutrients and the non-obesity components of the MetS. Two previous studies that have examined the association between aspects of dietary macronutrient intake and the MetS have also adjusted for total energy intake but not $\mathrm{BMI}^{(3,8)}$. McKeown et al. ${ }^{(3)}$ found no association between carbohydrate intake and the prevalence of the MetS after further adjustment for alcohol, PUFA and MUFA intake in a cohort of 2834 middle-aged subjects ${ }^{(3)}$. Freire et $a l .{ }^{(8)}$ focused on protein and fat intake in 877 middleaged Brazilian subjects of Japanese ethnicity ${ }^{(8)}$. In analyses adjusted for alcohol intake and dietary fibre, they found no association between protein and the MetS, and a positive association between fat intake and the MetS. The differences between the present results and those of these two previous studies may be related to dietary differences within the populations studied. Similarly, the differences in statistical adjustments may have contributed to these differences, especially when the coefficients in the statistical models are conditional on keeping the levels of the remaining covariates constant. Additionally, the majority of prior studies examining the association between dietary macronutrient composition and the prevalence of the MetS have not concurrently taken into account the impact of all macronutrients. By doing so, we have been able to describe a macronutrient hierarchy, with carbohydrate intake and protein intake at either end of the spectrum with regards to the association with the prevalence of the MetS. These findings are particularly pertinent considering the prevalence of popular dietary regimens that are based on the consumption of a specific ratio of macronutrients. As the weight-loss effects of these diets are principally due to adherence and energy intake, and not the macronutrient composition $^{(16)}$, altering the macronutrient balance may have its most important effects by influencing other cardiovascular risk factors. As such, the present results support the use of 
high-carbohydrate low-fat low-protein diets to reduce the risk of the MetS. However, one proposed mechanism by which low-carbohydrate high-fat high-protein diets may cause weight loss is by stimulating a decrease in energy intake, via decreased appetite ${ }^{(17)}$. As our models simulate energy-controlled conditions, the present results may have overestimated the detrimental metabolic effects of such low-carbohydrate high-fat high-protein diets. Although, given that individuals generally maintain a constant energy balance over time, we believe the present results highlight important, and potentially harmful, metabolic effects of diets high in either protein and/or fat.

Previous studies have shown that alcohol intake is either inversely associated with the prevalence of the MetS, or that there is a U-shaped relationship ${ }^{(9,18)}$. The present results indicate that this relationship is dependent on the macronutrient that is reduced in association with higher alcohol intake. While drinking up to one standard alcoholic drink per $d$ was associated with a reduced prevalence of the MetS when compared with non-drinkers, greater alcohol intake accompanied by an isoenergetic decrease in either protein or fat intake remained beneficial. When alcohol intake beyond one drink per d was associated with a concurrent reduction in carbohydrate intake, a U-shaped relationship with the prevalence of the MetS was apparent. Regarding the individual MetS components, the positive association between alcohol consumption and HDL-cholesterol is well established and is estimated to account for approximately $50 \%$ of the cardiovascular benefits of alcohol ${ }^{(19)}$. Regarding the association between alcohol intake and abdominal obesity, again the present results suggest that the association between the individual MetS components and alcohol intake are dependent on the consumption of other macronutrients. Wine-derived flavonoids may also influence both adipocyte physiology and glucose metabolism $^{(20)}$; however, their association with the MetS per se remains poorly understood.

There has been considerable debate recently regarding the various definitions of the MetS, and their association with disease $^{(21,22)}$. Our findings were similar, although sometimes weaker, when we used the NCEP-ATPIII definition of MetS $^{(23)}$, instead of the IDF definition (data not shown). This is probably due to abdominal obesity being a compulsory component of the IDF definition.

The present study has several limitations. First, due to the cross-sectional design, we cannot directly evaluate the impact of macronutrient intake on the incidence of the MetS. Second, the cohort studied consists entirely of subjects with at least one major cardiovascular risk factor, and as such presents a population at increased risk of CVD. Whether the observed associations are representative of the general population remains to be determined; however, given the highrisk nature of the subjects without the MetS in this cohort (including a high rate of obesity), the true association may have been underestimated. Third, we did not have sufficient data concerning dietary fibre intake to include in these analyses. Intake of cereal fibre, but not total dietary fibre, has been shown to be inversely associated with prevalence of the $\operatorname{MetS}^{(3)}$, and may underlie some of our observed associations involving carbohydrate intake. Finally, the observed total energy intake is relatively low for a cohort with a high rate of overweight and obesity. This is probably due to underreporting of energy intake as previously documented with $24 \mathrm{~h}$ dietary recalls in European populations ${ }^{(24)}$. As we primarily focused on dietary macronutrient composition (i.e. adjusted for total dietary energy intake), this underreporting is unlikely to have greatly influenced our findings ${ }^{(10)}$.

In conclusion, the present study indicates that a diet high in carbohydrates, low in fat and protein, and supplemented with regular low to moderate alcohol intake may be protective against the MetS; however, prospective cohort studies are required to better define this association.

\section{Acknowledgements}

M. R. S. was supported by a fellowship from the Fondation pour la Recherche Médicale, France. A. E. C. was supported by a PhD scholarship from the University of Sydney, and a research scholar award from the Cancer Institute New South Wales, Australia. M. R. S. contributed to the design of the analyses, undertook the analyses and drafted the manuscript. M. L. provided expert advice and contributed to the final manuscript. A. E. C. contributed to the design of the statistical models and critically reviewed the final manuscript. P. M. contributed to the set-up and management of the cohort, and contributed to the final manuscript. F. B. contributed to the final manuscript. There are no conflicts of interest to declare.

\section{References}

1. Lakka HM, Laaksonen DE, Lakka TA, Niskanen LK, Kumpusalo E, Tuomilehto J \& Salonen JT (2002) The metabolic syndrome and total and cardiovascular disease mortality in middle-aged men. JAMA 288, 2709-2716.

2. Sattar N, Gaw A, Scherbakova O, et al. (2003) Metabolic syndrome with and without C-reactive protein as a predictor of coronary heart disease and diabetes in the West of Scotland Coronary Prevention Study. Circulation 108, 414-419.

3. McKeown NM, Meigs JB, Liu S, Saltzman E, Wilson PW \& Jacques PF (2004) Carbohydrate nutrition, insulin resistance, and the prevalence of the metabolic syndrome in the Framingham Offspring Cohort. Diabetes Care 27, 538-546.

4. Zhu S, St-Onge MP, Heshka S \& Heymsfield SB (2004) Lifestyle behaviors associated with lower risk of having the metabolic syndrome. Metabolism 53, 1503-1511.

5. Park YW, Zhu S, Palaniappan L, Heshka S, Carnethon MR \& Heymsfield SB (2003) The metabolic syndrome: prevalence and associated risk factor findings in the US population from the Third National Health and Nutrition Examination Survey, 1988-1994. Arch Intern Med 163, 427-436.

6. Carnethon MR, Loria CM, Hill JO, Sidney S, Savage PJ \& Liu K (2004) Risk factors for the metabolic syndrome: the Coronary Artery Risk Development in Young Adults (CARDIA) study, 1985-2001. Diabetes Care 27, 2707-2715.

7. Park HS, Oh SW, Cho SI, Choi WH \& Kim YS (2004) The metabolic syndrome and associated lifestyle factors among South Korean adults. Int J Epidemiol 33, 328-336.

8. Freire RD, Cardoso MA, Gimeno SG \& Ferreira SR (2005) Dietary fat is associated with metabolic syndrome in Japanese Brazilians. Diabetes Care 28, 1779-1785.

9. Freiberg MS, Cabral HJ, Heeren TC, Vasan RS \& Curtis Ellison R (2004) Alcohol consumption and the prevalence of the metabolic syndrome in the US: a cross-sectional analysis of data from the Third National Health and Nutrition Examination Survey. Diabetes Care 27, 2954-2959. 
10. Willett W (2001) Commentary: dietary diaries versus food frequency questionnaires - a case of undigestible data. Int $J$ Epidemiol 30, 317-319.

11. Alberti KG, Zimmet P \& Shaw J (2005) The metabolic syndrome - a new worldwide definition. Lancet 366, 1059-1062.

12. Willett W \& Stampfer M (1998) Implications of total energy intake for epidemiologic analyses. In Nutritional Epidemiology, pp. 273-301 [W Willett, editor]. New York: Oxford University Press.

13. Jakes RW, Day NE, Luben R, Welch A, Bingham S, Mitchell J, Hennings S, Rennie K \& Wareham NJ (2004) Adjusting for energy intake - what measure to use in nutritional epidemiological studies? Int J Epidemiol 33, 1382-1386.

14. Altman DG \& Bland JM (2003) Interaction revisited: the difference between two estimates. BMJ 326, 219.

15. Eckel RH, Grundy SM \& Zimmet PZ (2005) The metabolic syndrome. Lancet 365, 1415-1428.

16. Dansinger ML, Gleason JA, Griffith JL, Selker HP \& Schaefer EJ (2005) Comparison of the Atkins, Ornish, Weight Watchers, and Zone diets for weight loss and heart disease risk reduction: a randomized trial. JAMA 293, 43-53.

17. Weigle DS, Breen PA, Matthys CC, Callahan HS, Meeuws KE, Burden VR \& Purnell JQ (2005) A high-protein diet induces sustained reductions in appetite, ad libitum caloric intake, and body weight despite compensatory changes in diurnal plasma leptin and ghrelin concentrations. Am J Clin Nutr 82, 41-48.
18. Yoon YS, Oh SW, Baik HW, Park HS \& Kim WY (2004) Alcohol consumption and the metabolic syndrome in Korean adults: the 1998 Korean National Health and Nutrition Examination Survey. Am J Clin Nutr 80, 217-224.

19. Pearson TA (1996) Alcohol and heart disease. Circulation 94, 3023-3025.

20. Strobel P, Allard C, Perez-Acle T, Calderon R, Aldunate R \& Leighton F (2005) Myricetin, quercetin and catechin-gallate inhibit glucose uptake in isolated rat adipocytes. Biochem $J$ 386, 471-478.

21. Qiao Q (2006) Comparison of different definitions of the metabolic syndrome in relation to cardiovascular mortality in European men and women. Diabetologia 49, 2837-2846.

22. Skilton MR, Moulin P, Serusclat A, Nony P \& Bonnet F (2007) A comparison of the NCEP-ATPIII, IDF and AHA/NHLBI metabolic syndrome definitions with relation to early carotid atherosclerosis in subjects with hypercholesterolemia or at risk of CVD: evidence for sex-specific differences. Atherosclerosis 190, 416-422.

23. Grundy SM, Cleeman JI, Daniels SR, et al. (2005) Diagnosis and management of the metabolic syndrome: an American Heart Association/National Heart, Lung, and Blood Institute Scientific Statement. Circulation 112, 2735-2752.

24. Ferrari P, Slimani N, Ciampi A, et al. (2002) Evaluation of under- and overreporting of energy intake in the 24-hour diet recalls in the European Prospective Investigation into Cancer and Nutrition (EPIC). Public Health Nutr 5, 1329-1345. 